Research Article

\title{
An Innovative Elastoplastic Analysis for Soft Surrounding Rock considering Supporting Opportunity Based on Drucker-Prager Strength Criterion
}

\author{
Rui Wang $\mathbb{D}^{1,2}$ Xu-dong Liu $\mathbb{D}^{1,2,3}$ Jian-biao Bai $\mathbb{i D}^{1,4}$ Shuai Yan $\mathbb{D}^{1,2}$ and Jun $\mathrm{Xu}^{5}$ \\ ${ }^{1}$ State Key Laboratory of Coal Resources and Safe Mining, China University of Mining and Technology, Xuzhou 221116, \\ Jiangsu, China \\ ${ }^{2}$ Key Laboratory of Deep Coal Resource Mining, Ministry of Education of China, School of Mines, \\ China University of Mining and Technology, Xuzhou 221116, Jiangsu, China \\ ${ }^{3}$ Taiyuan Coal Gas Group Transportation and Marketing Branch, Taiyuan 030021, Shanxi, China \\ ${ }^{4}$ Institute of Mining Engineering and Geology, Xinjiang Institute of Engineering, Urumqi 830091, China \\ ${ }^{5}$ School of Science, Yangzhou Polytechnic Institute, Yangzhou 225127, China
}

Correspondence should be addressed to Xu-dong Liu; lxd1118@126.com and Jian-biao Bai; baijianbiao@cumt.edu.cn

Received 7 February 2021; Revised 2 March 2021; Accepted 6 March 2021; Published 25 March 2021

Academic Editor: Zhijie Zhu

Copyright (c) 2021 Rui Wang et al. This is an open access article distributed under the Creative Commons Attribution License, which permits unrestricted use, distribution, and reproduction in any medium, provided the original work is properly cited.

\begin{abstract}
In order to study the mechanism of excavation and supporting process of equivalent circular roadway, the model of soft roadway was established firstly. The elastoplastic solutions in excavation process were deduced based on Drucker-Prager strength criterion. Then, the elastoplastic solution under supporting condition was obtained based on homogenization method under the condition of rockbolts and liner supporting. Lastly, an example was analyzed to study the effect of different factors such as "space effect," supporting opportunity, stresses, surrounding displacement, and the radius of plastic zone. Based on theoretical research case, the change rules of considering the "space effect" and the supporting opportunity when calculating the subarea of the roadway were discussed, the control of interval distance of rockbolts on the displacement of surrounding rock mainly reflecting in the plastic residual zone and the "space effect" in excavation, and the supporting time to control the displacement of surrounding rock not being ignored are revealed. The results can provide an important theoretical basis for the stability evaluation and quantitative support design of roadway surrounding rock. Therefore, the "space effect" and the supporting time to control the displacement and stresses of surrounding rock can not being ignored in underground engineering.
\end{abstract}

\section{Introduction}

Coal has long been the main energy source in China $[1,2]$. In view of the exhaustion of shallow resources in recent years, the resource exploitation and space development gradually have been transferred to the deep earth [3,4]. The complex mechanical environment of "three heights and one disturbance" in deep coal and rock body leads to many problems and challenges in deep mining $[5,6]$. They lead to the strength degradation of rock mass, which affects the stability of underground engineering [7]. The development and establishment of new theories and methods are the theoretical basis of surrounding rock control in deep underground engineering, which is of great significance to guide the surrounding rock control technology and engineering practice of kilometer deep roadway.

The stress and plastic zone distribution state of surrounding rock of deep roadway is an important basis for evaluating the stability of surrounding rock and the reliability of quantitative support design. In the past, many researchers [8-13] have done research on circular tunnel problems in an elastoplastic, elasto-brittle-plastic, and strain-softening way. Generally, the Mohr-Coulomb criteria, Hoek-Brown criteria, and generalized Hoek-Brown 
criteria are employed as associated and nonassociated potential flow laws. On this basis, the surrounding rock stress and deformation distribution is analyzed by ideal elastoplastic and elasto-brittle-plastic mechanical models. However, engineering practices show that, applying to the different strength criteria, the stress state and plastic zone of the surrounding rock are different. Therefore, choosing the appropriate strength criterion can make the mechanical state of surrounding rock closer to engineering practice. What is more, the elastic-plastic solution of surrounding rock under supporting condition could be obtained, and the deformation of surrounding rock may be too large in the process of soft rock roadway excavation, which affects the safety of chamber construction seriously.

At present, the supporting theory of surrounding rock after excavation has become mature, and many scholars have done a lot of research in this respect [14-20]. Although the elastic-plastic solution of surrounding rock under supporting condition is obtained, the deformation of surrounding rock may be too large in the process of soft rock chamber excavation, which affects the safety of roadway construction seriously. So, the supporting time should be considered, and it should be considered earlier than before. In summary, it is urgent to develop the theoretical study of supporting time in the process of roadway excavation. Due to the traditional elastic-plastic analysis of the roadway based on two-dimensional plane strain, considering the "space effect" can analyze the stress, displacement, and other analytical changes caused by threedimensional excavation of the roadway. Both theory and practice have shown that, after roadway excavation, most of the rock mass is still in the state of three directions. In addition to the maximum and minimum principal stress, the magnitude of intermediate principal stress also has an important effect on the deformation and failure of roadway surrounding rock.

Based on the Drucker-Prager (D-P) strength criterion and noncorrelation flow rule, this paper analyzes the fact that brittle fracture zone exists obviously in deep roadway. The closed analytical solutions of stress field, displacement field, and plastic zone radius of roadway are derived. The influence of different parameters on the stress, deformation, and plastic zone radius of surrounding rock is studied. The results can provide important theoretical basis for the stability evaluation and support design of surrounding rock.

\section{Theoretical Model}

In the process of excavation, the excavation surface of roadway is within a certain range, and the development of elastoplastic deformation and stress redistribution of surrounding rock are restricted by its own constraints, which leads to the fact that the deformation of surrounding rock cannot be fully released. Stress redistribution cannot be completed quickly, called excavation "space effect ." Considering the "space effect" of excavation, the timely support of roadway has theoretical basis. With the advance of excavation facing forward, the virtual support force is gradually released with the secondary deformation of surrounding rock, while the pretightening force of the actual support of roadway increases gradually, and the stability of surrounding rock is maintained.

According to the failure characteristics of the surrounding rock of the roadway, the zoning of the surrounding rock of the circular roadway is shown in Figure 1 and the following assumptions are made:

(1) The roadway is considered to be infinite long, and the rock mass is isotropic approximately and homogeneous continuous medium;

(2) The section of roadway is circular, and the radius of the roadway is $R_{0}$, and the radii of residual plastic zone, softening plastic zone, and elastic zone are $R_{r}$, $R_{s}$ and $R_{e}$;

(3) Before excavation, the surrounding rock of roadway is in the hydrostatic pressure field; that is, the original rock stress is $\sigma_{0}, \mathrm{MPa}$. And supporting lining structure provides supporting resistance $p_{\mathrm{i}} . \sigma_{r}, \sigma_{\theta}$ are defined by the radial stress and the circumferential stress of the roadway, respectively, and $\sigma_{\theta}>\sigma_{r}$ are satisfied. $\varepsilon_{\theta}, \varepsilon_{r}$ are defined by the radial and circumferential strain of the surrounding rock, respectively. In the following upper corner marks, " $e$ ", " $s$ " and " $r$ " denote the amount of elastic zone, plastic softening zone, and plastic residual zone, respectively.

\section{Drucker-Prager Strength Criterion}

At present, the Drucker-Prager strength criterion has been applied to lots of finite element numerical modeling software; meanwhile, Drucker-Prager criterion is a linear expression of the generalized Mises criterion. The effects of the intermediate principal stress and the hydrostatic pressure on the yield characteristics of rock materials are considered. Hence, the Drucker-Prager criterion is adopted in this paper, and its form is given in the following equation [21]:

$$
f\left(I_{1}, \sqrt{J_{2}}\right)=\sqrt{J_{2}}-\beta I_{1}-k_{f}=0,
$$

where $I_{1}$ is the first stress invariant, and $J_{2}$ is the second stress deviation invariant.

Regarding the values of $\beta$ and $k_{f}$, it is usually to associate the D-P criterion with the M-C criterion, that is, to think that the D-P criterion is a smooth approximate treatment method for the $\mathrm{M}-\mathrm{C}$ criterion to remove angular points (also singular points) on the $\pi$ plane, because the $D-P$ criterion is a circle on the $\pi$ plane. The characteristics of tensile resistance, different compressive strength, and the effect of the intermediate principal stress on the material need to be considered since the coal and rock mass are a strength differential (SD) material [22-27] with different compressive properties, and the elastic core zone is in a triaxial stress state.

If $\sigma_{1}, \sigma_{2}$ and $\sigma_{3}$ are assumed to be maximum principal stress, intermediate principal stress, and minimum principal stress, and then the specific expressions of $I_{1}$ and $J_{2}$ are, respectively, 


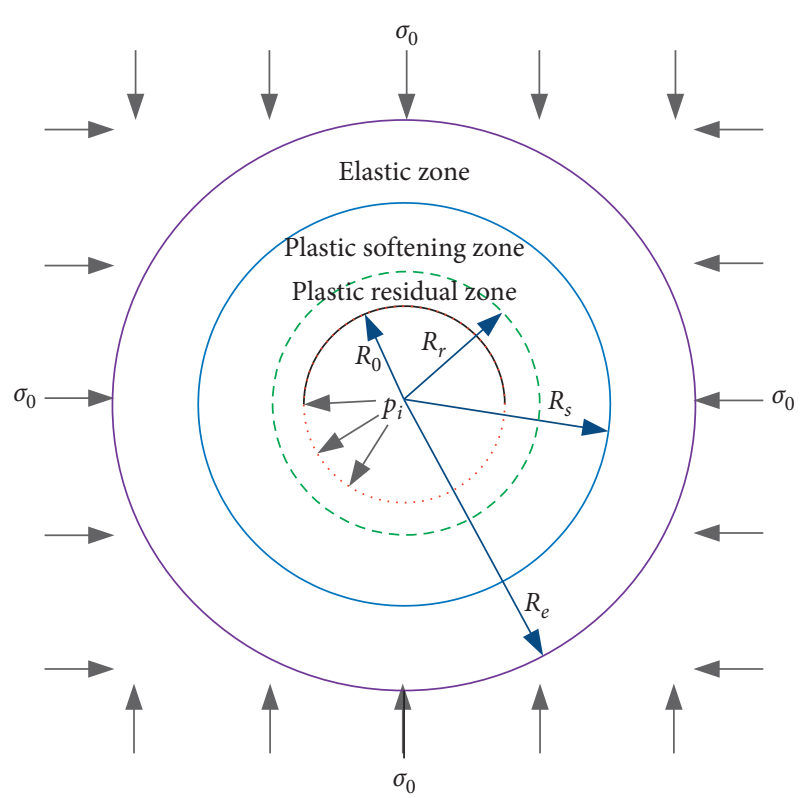

FIGURE 1: Elastoplastic deformation zones of surrounding rock around circular roadway.

$$
\begin{aligned}
& I_{1}=\sigma_{1}+\sigma_{2}+\sigma_{3}, \\
& J_{2}=\frac{\left(\sigma_{1}-\sigma_{2}\right)^{2}+\left(\sigma_{1}-\sigma_{3}\right)^{2}+\left(\sigma_{2}-\sigma_{3}\right)^{2}}{6} .
\end{aligned}
$$

To simplify the selection of the parameters in the Drucker-Prager criterion, the converted relationship between $\beta, k_{f}$, the internal frictional angle $(\varphi)$, and the cohesion (c) in the Mohr-Coulomb criterion with the plane strain assumption is provided in equation (3).

$$
\begin{gathered}
k_{f}=\frac{\sqrt{3} c \cos \varphi}{\sqrt{3+\sin ^{2} \varphi}}, \\
\beta=\frac{\sin \varphi}{\sqrt{9+3 \sin ^{2} \varphi}} .
\end{gathered}
$$

In practical engineering, the intermediate principal stress coefficient $m$ is often introduced to indicate the relationship between the three principal stresses:

$$
m=\frac{\left(\sigma_{2}-\sigma_{3}\right)}{\left(\sigma_{1}-\sigma_{3}\right)},
$$

where $0 \leq m \leq 1$, and the greater the $m$, the greater the effect of the intermediate principal stress, and the smaller the effect.

Equation (4) is simplified, then substituting in equations (2a) and (2b),

$$
\begin{aligned}
I_{1} & =(1+m) \sigma_{1}+(2-m) \sigma_{3}, \\
\sqrt{J_{2}} & =\sqrt{\frac{m^{2}-m+1}{3}}\left(\sigma_{1}-\sigma_{3}\right)=\lambda_{m}\left(\sigma_{1}-\sigma_{3}\right),
\end{aligned}
$$

where $\lambda_{m}=\sqrt{\left(m^{2}-m+1\right) / 3}$.

By substituting equations (5a), (5b) into equation (1), the expression of D-P criterion including to the parameters $m$, $\lambda_{m}, \beta, k_{f}$ is derived:

$$
f=\left(\lambda_{m}-m \beta-\beta\right) \sigma_{1}-\left(\lambda_{m}-m \beta+2 \beta\right) \sigma_{3}-k_{f}=0 .
$$

3.1. Initial Bearing Capacity. Elastic-plastic problem of surrounding rock of roadway can be regarded as plane strain problem. When the support resistance and original rock stress meet the $p_{i}<\sigma_{0}$, it is generally considered that the stress state of surrounding rock satisfies the following relationship:

$$
\left\{\begin{array}{l}
\sigma_{1}=\sigma_{\theta}, \\
\sigma_{3}=\sigma_{r} .
\end{array}\right.
$$

According to the finite element simulation results, it is pointed out that, due to the influence of "space effect" on the working surface of roadway, the released load acting on the roadway excavation section will not immediately reach the initial in situ stress state but has a time course. The release load varies with time,

$$
p_{0}(t)=p_{0}\left(1-0.7 e^{-\left(3.15 V / 2 R_{0}\right) t}\right),
$$

where $R_{0}$ is the radius of circular roadway, $m ; V$ is the average speed of roadway excavation, $\mathrm{m} / \mathrm{d} ; t$ is the starting time of the moment of excavation from section. The default value in this paper $t=1 \mathrm{~d}$, so different roadway velocities represent different distances between section and excavation surface.

The expression of "virtual support resistance" of "space effect" roadway is

$$
p_{i}^{*}=p_{0}-p_{0}(t)=0.7 p_{0} e^{-\left(3.15 V / 2 R_{0}\right) t} .
$$

At this point, the bearing capacity $p_{c}$ of the initial support can be expressed as

$$
p_{c}=p_{i}^{*}+p_{i}
$$

\subsection{Plastic Flow Equation (Definition of Dilatancy} Coefficient). Considering the dilatation of rock mass in plastic softening zone and plastic residual zone, the relationship between dilatancy coefficient and strain is shown in Figure 2.

The dilatation of rock mass in plastic softening zone and plastic residual zone is considered.

$$
\Delta \varepsilon_{r}^{s}+\eta_{1} \Delta \varepsilon_{\theta}^{s}=0
$$

where $\eta_{1}$ is the dilatancy coefficient of plastic softening zone, and its value is greater than 1 .

The plastic deformation of rock is nonlinear and generally satisfies the noncorrelated flow rule, which can be determined by the plastic potential function $(\varphi)$. The yield function $(f)$ and $\varphi$ have the same expression form. The internal friction angle $(\varphi)$ in $f$ can be transformed into the 


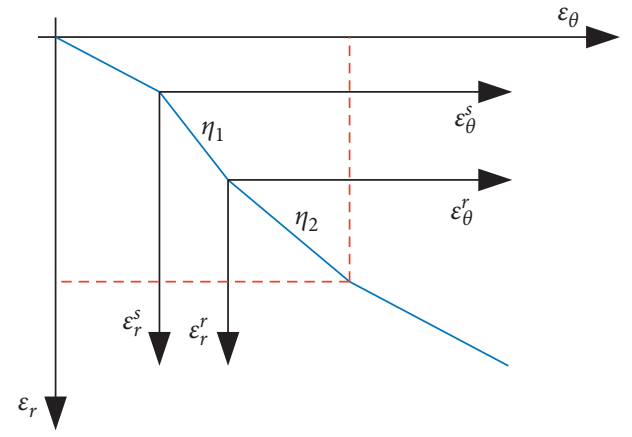

FIGURE 2: The strain model of soft rock [28].

shear dilatancy angle $\psi$. The expression of plastic potential function is

$$
\phi=\left(\sigma_{\theta}, \sigma_{r}\right)=\sigma_{\theta}-A_{i, \psi} \sigma_{r}
$$

where $A_{i, \psi}$ is the rock material parameter.

According to the plastic potential theory,

$$
\mathrm{d} \varepsilon_{i j}^{p}=\mathrm{d} \lambda\left(\partial \phi / \partial \sigma_{i j}\right)
$$

where $d \varepsilon_{i j}^{p}, \sigma_{i j}$ are the plastic strain increment and stress tensor, respectively; $d \lambda$ is a constant related to the plastic potential function.

According to the nonassociated flow rule of dilatation of rock mass in the plastic residual zone, we have

$$
\Delta \varepsilon_{r}^{r}+\eta_{2} \Delta \varepsilon_{\theta}^{r}=0
$$

where $\Delta \varepsilon_{r}^{r}, \Delta \varepsilon_{\theta}^{r}$ are the radial and circumferential strain increments in the plastic residual zone, respectively; $\eta_{2}$ is the dilatancy coefficient in the plastic residual zone, and its range is $1.3-1.5$ generally.

\section{Elastoplastic Analysis of Surrounding Rock before Supporting Roadways}

4.1. Basic Equation. According to the elastoplastic theory, the surrounding rock satisfies the equilibrium equation:

$$
\frac{\mathrm{d} \sigma_{r}}{\mathrm{~d} r}+\frac{\left(\sigma_{r}-\sigma_{\theta}\right)}{r}=0
$$

Geometric equation:

$$
\left\{\begin{array}{l}
\varepsilon_{r}=\frac{\mathrm{d} u}{\mathrm{~d} r}, \\
\varepsilon_{\theta}=\frac{u}{r},
\end{array}\right.
$$

where $u$ is the radial displacement of the surrounding rock.

Constitutive equations satisfying the plane strain are shown:

$$
\left\{\begin{array}{l}
\varepsilon_{r}=\frac{1-\mu^{2}}{E}\left(\sigma_{r}-\frac{1-\mu}{\mu} \sigma_{\theta}\right), \\
\varepsilon_{\theta}=\frac{1-\mu^{2}}{E}\left(\sigma_{\theta}-\frac{1-\mu}{\mu} \sigma_{r}\right) .
\end{array}\right.
$$

4.2. Stresses and Displacement in Elastic Zone. When considering the "space effect," the stresses of elastic zone are

$$
\left\{\begin{array}{l}
\sigma_{\theta}^{e}=p_{0}\left(1+r_{0}^{2} / r^{2}\right)-\frac{p_{c}(t) r_{0}^{2}}{r^{2}} \\
\sigma_{r}^{e}=p_{0}\left(1-r_{0}^{2} / r^{2}\right)+\frac{p_{c}(t) r_{0}^{2}}{r^{2}}
\end{array}\right.
$$

Radial displacement is

$$
u^{e}=\frac{(1+\mu) r}{E}\left[p_{0}(1-2 \mu)+p(t)\left(\frac{r_{0}}{r}\right)^{2}\right],
$$

where $\mu$ is Poisson's ratio of rock mass.

4.3. Stress and Displacement in Plastic Softening Zone. The total strains in plastic softening zone consist of elastic strain and plastic strain. The strains in plastic softening zone are

$$
\left\{\begin{array}{l}
\varepsilon_{r}=\left(\varepsilon_{r}^{s}\right)_{r=R_{s}}+\Delta \varepsilon_{r}^{s}, \\
\varepsilon_{\theta}=\left(\varepsilon_{\theta}^{s}\right)_{r=R_{s}}+\Delta \varepsilon_{\theta}^{s} .
\end{array}\right.
$$

The compatible equation of displacement in plastic softening zone can be obtained from eqs. (20), (16), and (14), and the displacement at the boundary condition $r=R_{s}$ can be obtained continuously.

$$
\begin{aligned}
u^{s}= & \frac{R_{s}}{\left(1+\eta_{1}\right)\left(1+\eta_{2}\right)}\left[\left(\eta_{2}-1\right) I+\left(\eta_{2}+\eta_{1}\right) G\right]\left(\frac{R_{s}}{r}\right)^{n_{2}} \\
& +\frac{r}{\left(1+\eta_{1}\right)\left(1+\eta_{2}\right)}\left[2 I+\left(1-\eta_{1}\right) G\right],
\end{aligned}
$$

where $G=\left(2(1+u)\left(p_{0}-p_{\mathrm{c}}\right) / E\right)\left(r_{0} / R_{\mathrm{e}}\right)^{2}\left(R_{\mathrm{s}} / r\right)^{1+\eta_{1}}, \quad I=$ $(1+u / E)\left[p_{0}(1-2 u)\left(1+\eta_{1}\right)+p(t)\left(r_{0} / R_{e}\right)^{2}\left(\eta_{1}-1\right)\right]$.

The radial stresses are derived by connecting eq. (15) when $r=R_{s}$,

$$
\begin{aligned}
\sigma_{r}^{s}= & Q\left(\frac{r}{R_{e}}\right)^{k-1}-\frac{\sigma_{c}^{m}-\sigma_{c}^{*}}{1-\left(R_{e} / R_{s}\right)^{1+\eta_{2}}}\left[\frac{1}{1-k}+\frac{1}{\eta_{2}+k}\left(\frac{R_{s}}{r}\right)^{1+\eta_{2}}\right] \\
& +\frac{\sigma_{c}^{m}}{1-k},
\end{aligned}
$$$$
\sigma_{\theta}^{s}=k \sigma_{r}^{s}+\sigma_{c}^{s} \text {, }
$$

where $Q=\left(r / R_{e}\right)^{k-1}\left[p_{0}-p(t)\left(r / R_{e}\right)^{2}+\left(D / \eta_{1}+k\right)-\left(\sigma_{c}^{m}-\right.\right.$ $\left.\left.D\left(R_{e} / R_{s}\right)^{1+\eta_{1}} / 1-k\right)\right]-\left(\left(\eta_{1}+1\right) D /\left(\eta_{1}+k\right)(1-k)\right)\left(R_{e} / R_{s}\right)^{1+\eta_{1}}$ $+\left(\left(\sigma_{c}^{m}-\sigma_{c}^{r}\right) / 1-\left(R_{e} / R_{s}\right)^{1+\eta_{2}}\right)\left(1+\eta_{2} /\left(\eta_{2}+k\right)(1-k)\right), \quad \sigma_{c}^{s}=\sigma_{c}^{m}$ $-\left(\left[1-\left(R_{s} / r\right)^{1+\eta_{2}}\right]\left(\sigma_{c}^{m}-\sigma_{c}^{r}\right) / 1-\left(R_{s} / R_{r}\right)^{1+\eta_{2}}\right), D=\left(2\left(\sigma_{c}^{m}-\sigma_{c}\right)\right.$ $p(t)\left(r_{0} / R_{e}\right)^{2} / p_{0}(1-2 \mu) \eta_{1}+p(t)\left(r_{0} / R_{e}\right)^{2}\left[\eta_{1}-2+2\left(R_{e} /\right.\right.$ $\left.\left.\left.R_{s}\right)^{1+\eta_{1}}\right]\right) . \varphi$ is the internal friction angle of rock mass. $\sigma_{c}, \sigma_{c}^{m}$, and $\sigma_{c}^{r}$ are the yield strength, peak strength, and residual strength of rock mass, respectively. 
4.4. Stress and Displacement in Plastic Residual Zone. The strains in plastic residual zone are

$$
\left\{\begin{array}{l}
\varepsilon_{r}=\left(\varepsilon_{r}^{p}\right)_{r=R_{r}}+\Delta \varepsilon_{r}^{r} \\
\varepsilon_{\theta}=\left(\varepsilon_{\theta}^{p}\right)_{r=R_{r}}+\Delta \varepsilon_{\theta}^{r} .
\end{array}\right.
$$

The displacement solution process is consistent with the plastic softening zone, and the differential equation can be obtained:

$$
\frac{\mathrm{d} u}{\mathrm{~d} r}+\eta_{2} \frac{u}{r}=A
$$

where $A=M-N p_{i}^{*}, \quad M=\left[\left((1+\mu)\left(1+\xi_{2}\right)(1-2 \mu) / E\right)+\right.$ 1] $p_{0}, N=\left((1+\mu) \quad\left(1+\xi_{2}\right)\left(r_{0} / R_{r}\right)\left[\left(\xi_{1}-1\right)+\left(2\left(\xi_{2}-\xi_{1}\right) /\right.\right.\right.$ $\left.\left.\left.1+\xi_{2}\right)\left(R_{s} / R_{r}\right)^{\left(1+\xi_{1}\right)}\right] / E+\left(1+\xi_{1}\right)\right)$.

The compatible equation of displacement in this zone can be obtained from eqs. (25), (15), and (13), and the displacement at the boundary condition $r=R_{r}$ can be obtained continuously.

$$
u^{r}=r\left[\frac{A}{1+\eta_{2}}+\frac{2(1+\mu)\left(p_{0}-p_{c}\right)\left(r_{0} / R_{s}\right)^{2}\left(R_{s} / R_{r}\right)^{1+\eta_{1}}\left(R_{r} / r\right)^{1+\eta_{2}}}{E\left(1+\eta_{2}\right)}\right]
$$

The radial stresses can be obtained by combining eq (15) when $r=R_{r}$,

$$
\begin{aligned}
\sigma_{r}^{r}= & \left\{Q\left(\frac{R_{r}}{R_{e}}\right)^{k-1}-\frac{\sigma_{c}^{m}-\sigma_{c}^{b}}{1-\left(R_{e} / R_{s}\right)^{1+\eta_{2}}}\left[\frac{1}{1-k}+\frac{1}{\eta_{2}+k}\left(\frac{R_{s}}{R_{r}}\right)^{1+\eta_{2}}\right]\right. \\
& \left.+\frac{\sigma_{c}^{m}-\sigma_{c}^{b}}{1-k}\right\} \cdot\left(\frac{r}{R_{r}}\right)^{k-1}+\frac{\sigma_{c}^{r}}{1-k},
\end{aligned}
$$$$
\sigma_{\theta}^{\mathrm{r}}=k \sigma_{r}^{\mathrm{r}}+\sigma_{c}^{r}
$$

4.5. Plastic Softening Zone and Plastic Residual Zone. At the boundary of the plastic softening zone and the plastic residual zone (i.e., $r=R_{r}$ ), the strength parameter of plastic softening zone softens to the residual strength value. So the ratio of radius of plastic residual zone to radius of plastic softening zone is

$$
\left\{\begin{array}{l}
\frac{R_{s}}{R_{r}}=\left[\frac{c_{0}-c_{r}+J}{J}\left(\frac{R_{s}}{r_{0}}\right)^{2}\right]^{\left(1 / 1+\eta_{1}\right)}, \\
J=\frac{2 F(1+\mu)\left(p_{0}-p_{c}\right)}{E\left(1+\eta_{1}\right)}
\end{array}\right.
$$

At the boundary of the elastic zone and the plastic softening zone (i.e., $r=R_{s}$ ), the radius of the plastic softening zone can be obtained:

$$
R_{s}=r_{0} \sqrt{\frac{\left(p_{0}-p_{c}\right)\left(1+k_{\varphi}\right)}{\left(k_{\varphi}-1\right) p_{0}+\sigma_{c}}}
$$

The radius of the plastic residual zone can be obtained by combining eqs. (29) and. (30):

$$
R_{r}=r_{0} \sqrt{\frac{\left(p_{0}-p_{c}\right)\left(1+k_{\varphi}\right)}{\left(k_{\varphi}-1\right) p_{0}+\sigma_{c}}}\left[\frac{J}{c_{0}-c_{r}+J}\left(\frac{r_{0}}{R_{s}}\right)^{2}\right]^{\left(1 / 1+\eta_{1}\right)} .
$$

\section{Coupling Effect between Supporting Structures and Surrounding Rock}

Assuming that the bolts and liners of the supporting structure are contacting with the surrounding rock closely, the coupling between the bolt and the surrounding rock is considered as a composite bearing body, and the time difference between bolts and liners is 0 approximately. In addition, considering the timeliness of concrete strength hardening, rockbolts and liners bear the load of surrounding rock together.

5.1. Equivalent Material Parameters under Coupling Effect of Surrounding Rock and Rockbolts. Because of the supporting force between rockbolts and surrounding rock acting on the surrounding rock in the form of equivalent volume force, the stresses and the displacement of plastic softening zone change nonlinearly. When the rockbolt anchoring acts on these two sections, it is more complicated to solve the stresses and displacement of surrounding rock.

According to reference [29], using homogenization method, bolts are uniformly arranged. Bolts and surrounding rock are regarded as equivalent materials, and its elastic modulus expression is as follows

$$
E^{*}=\frac{E_{b} \pi r_{b}^{2}+E\left(f_{1} f_{2}-\pi r_{b}^{2}\right)}{f_{1} f_{2}}
$$

where $E_{b}$ is the elastic modulus of bolt; $r_{b}$ is the diameter of bolt; $E$ is the elastic modulus of surrounding rock; $f_{1}$ is the row spacing of bolt, $f_{2}$ is the hoop spacing of bolt.

When the plastic zone is formed after the excavation of the surrounding rock, the internal friction angle changes to be smaller than that of the elastic zone. When the bolt is applied in the plastic zone, the internal friction angle will be close to the elastic zone. According to reference [30], the equivalent material cohesive force of bolt pretightening force should be considered, and the equivalent material cohesive force is

$$
c^{*}=c_{i}+c_{j}+c_{t}
$$

where $c_{i}$ is the cohesion of each zone, and the cohesion of the elastic zone, the plastic softening zone, and the plastic residual zone is $c_{0}, c_{s}$ and $c_{r}$, respectively; $c_{j}$ is the cohesion force of the rockbolt and $c_{\mathrm{j}}=\sigma_{\mathrm{s}} \pi r_{\mathrm{b}}^{2} / 4 \sqrt{3} f_{1} f_{2} \cos \left(45^{\circ}-\varphi\right)$. In this equation, $\sigma_{s}$ is the yield strength of the rockbolt; $c_{t}$ is the additional cohesion force formed by the pretightening force of rockbolt and $c_{\mathrm{t}}=\left(F_{0} / f_{1} f_{2}\right) \cos \left(45^{\circ}-\varphi\right) \tan \varphi$. In this equation, $F_{0}$ is the pretightening force of rockbolt. 
The stresses, displacement, and the zoning range of surrounding rock after rockbolt supporting can be obtained by substituting the equivalent material parameters $E^{*}$ and $c^{*}$ into the above equations.

\subsection{Displacement Analysis of Concrete Shotcrete Supporting.} The supporting resistance is provided by passive compression after spraying, but the strength required for the bearing capacity of the spraying layer needs a time course. The strength is mainly related to the elastic modulus.

According to reference [31], the elastic modulus can be obtained:

$$
E(t)=\left\{\begin{array}{l}
E_{0}\left[\alpha+\beta \lg \left(1+\frac{t}{t_{1}}\right)\right], \quad\left(t_{0}<t<t_{1}\right), \\
E_{0}, \quad\left(t \geq t_{1}\right),
\end{array}\right.
$$

where $E_{0}$ is the ultimate elastic modulus of concrete shotcrete layer; $t_{1}$ is the time of concrete shotcrete layer achieving the design strength.

When the rockbolts and surrounding rock are regarded as composite bearing body, the load of composite bearing body is assumed by lining supporting resistance and virtual supporting force. The radial displacement of the plastic residual zone is expressed as follows:

$$
\left.u^{r}\right|_{r=r_{0}}=r_{0} h_{3}\left[p_{i}(t)+p_{1}(t)\right]
$$

For a given time increment $\Delta t$, the radial displacement increment of the plastic residual zone is

$$
\left.\Delta u^{r}\right|_{r=r_{0}}=r_{0} h_{3}\left[\frac{\mathrm{d} p_{i}(t)}{\mathrm{d} t} \Delta t+\frac{\mathrm{d} p_{1}(t)}{\mathrm{d} t} \Delta t\right] .
$$

The concrete spray layer is equivalent to the curved beam with stiffness $K_{\mathrm{c}}$ as the incremental constitutive equation of the roadway. The equation is

$$
\frac{\left.\Delta u^{r}\right|_{r=r_{0}}}{r_{0}}=\frac{\Delta t}{K_{c}} \frac{\mathrm{d} p_{i}(t)}{\mathrm{d} t}
$$

where $\quad K_{\mathrm{c}}=\left(E(t)\left(r_{0}^{2}-a^{2}\right)\right) /\left(\left(1+\mu_{0}\right)\left[\left(1-2 \mu_{0}\right) r_{0}^{2}+a^{2}\right]\right)$, $\mu_{0}$ is Poisson's ratio of the concrete sprayed layer, and $a$ is the inner diameter of the concrete sprayed layer.

According to eq. (37), we can obtain

$$
\left.\Delta u^{r}\right|_{r=r_{0}}=\frac{r_{0} h_{3}}{1-K_{c} h_{3}} \int_{t_{0}}^{t} \frac{\mathrm{d} p_{1}(s)}{\mathrm{d} s} \mathrm{~d} s .
$$

\section{Example Analysis}

The basic parameters of circular roadway design are as follows: radius of roadway $r_{0}=3 \mathrm{~m}$, elastic modulus $E=$ 2.0 GPa, Poisson's ratio $\mu=0.32$, crustal stress $p_{0}=20 \mathrm{MPa}$, initial cohesion $c_{0}=0.8 \mathrm{MPa}$, peak hardening cohesion $c_{m}=1.6 \mathrm{MPa}$, residual cohesion $c_{r}=0.4 \mathrm{MPa}$, internal friction angle $=30^{\circ}$, and initial support force $p_{i}=0 \mathrm{MPa}$. The rockbolts cover the plastic zone, and the specific parameters are as follows: modulus of elasticity $E_{b}=210 \mathrm{GPa}$, yield strength $\sigma_{b}=345 \mathrm{MPa}$, pretightening force $F=60 \mathrm{kN}$, $r_{b}=20 \mathrm{~mm}$, row spacing, and hoop spacing $f_{1}=f_{2}=800 \mathrm{~mm}$. The lining parameters are as follows: elastic modulus $E_{0}=2.8 \times 10^{4} \mathrm{MPa}, r_{0}-a=0.25 \mathrm{~m}$. When considering the supporting time, the excavation progress is $V=5 \mathrm{~m} / \mathrm{d}$, and the excavation section follows the principle of excavation to support. Before and after supporting, the roadway area is shown in Table $1[13,25,28]$.

As shown in Table 1, the thickness of plastic residual zone is $1.87 \mathrm{~m}$ under high crustal stress and only $0.96 \mathrm{~m}$ under the supporting. The supporting can reduce the range of plastic zone effectively. When considering the "space effect," the range of plastic zones is further reduced. In addition, the more nearer the distance between the excavation face and the supporting surface, the more obvious the "space effect."

6.1. The Influence of Spacing-Row of Rockbolts between the Stresses and Displacement. As shown in Figure 3, the larger the distance between rows, the smaller the circumferential stress and radial stress, and the peak value of circumferential stress moves away from the center of the roadway, which is not conducive to the safety of the roadway. The radial stress has an inflection point at the radius of the plastic softening zone, developing faster in the plastic softening zone. In the plastic softening zone, the circumferential stress increases sharply, while the elastic zone tends to be stable. Although the reduction of row spacing between rockbolts can increase the stress of surrounding rock and strengthen the bearing capacity of plastic zone, the increasement is not obvious.

Figure 4 shows that the displacement of surrounding rock increases with the distance increasement of spacingrow of rockbolts. The displacement of plastic zone is mainly affected by the distance of spacing-row of rockbolts. But the displacement of elastic zone is almost negligible. When the distance between spacing-row of rockbolts is $1.2 \mathrm{~m}$, the displacement of surrounding rock is compared with that of the spacing-row of rockbolts, which is $0.4 \mathrm{~m}$. The displacement of the latter is $35.6 \%$ less than that of the former. The influence of spacing-row of rockbolts is mainly reflecting in the displacement of surrounding rock.

\subsection{Effect of "Space Effect" and Support Time on Displacement} of Surrounding Rock in Roadway. The distance between the excavation face and the supporting surface is defined as $x$ and $x=V t_{0}$. So, $x$ is related to the "space effect." The influence of "space effect" on the displacement of surrounding rock is shown in Figure 5. The smaller the value $x$ is, the greater the virtual supporting resistance is, and the shorter the distance between the supporting surface and the excavation surface is. So, the smaller the radial displacement of the tunnel wall is, the more favorable the stability of the roadway is. The displacement of the surrounding rock at $x=15 \mathrm{~m}$ is compared with the displacement without considering the "space effect" and the supporting time, and the displacement of the former is $95.9 \%$ of that of the latter when the displacement of surrounding rock is equal to $r=3 \mathrm{~m}$. Therefore, when the displacement of surrounding rock is 
TABLE 1: The zones' ranges of surrounding rock of roadway.

\begin{tabular}{lccc}
\hline Consideration of factors & Plastic residual zone $(\mathrm{m})$ & Plastic softening zone $(\mathrm{m})$ & Elastic zone $(\mathrm{m})$ \\
\hline No- supporting & 4.77 & 6.58 & \\
Supporting & 3.86 & 5.60 & $\infty$ \\
Supporting (considering "space effect" $V=10 \mathrm{~m} / \mathrm{d})$ & 3.83 & 5.55 & $\infty$ \\
Supporting (considering "space effect" $V=6 \mathrm{~m} / \mathrm{d})$ & 3.79 & 5.48 & $\infty$ \\
Supporting (considering "space effect" $V=3 \mathrm{~m} / \mathrm{d})$ & 3.71 & 5.32 & $\infty$ \\
\hline
\end{tabular}

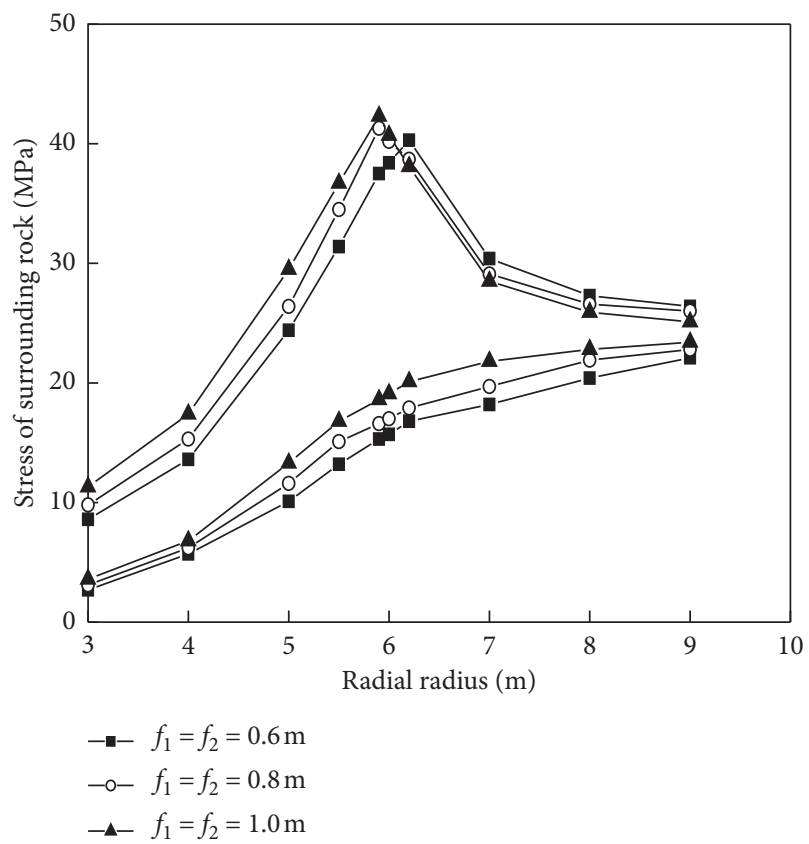

Figure 3: The influence of spacing-row of rockbolts to stress of surrounding rock.

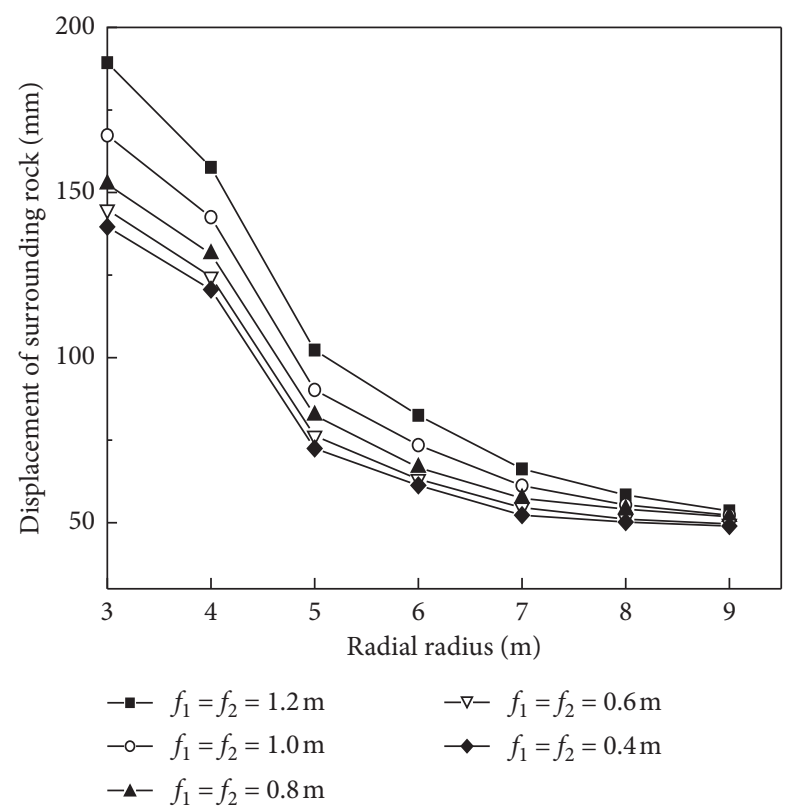

FIgURE 4: The influence of spacing-row of rockbolts to displacement of surrounding rock.

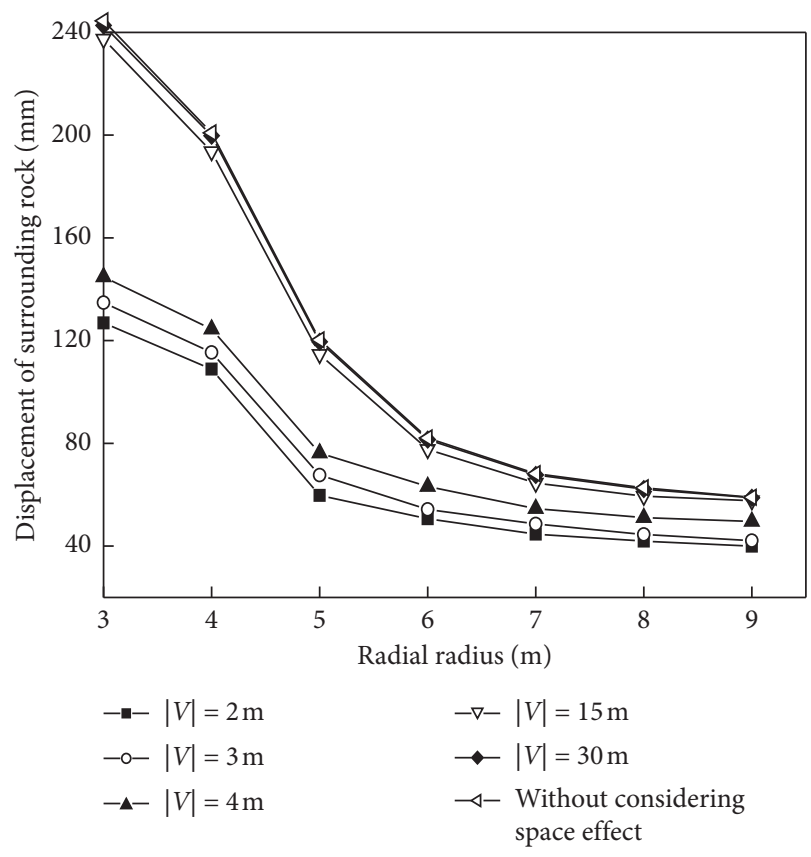

FIGURE 5: The influence of space effect on surrounding rock displacement of roadway.

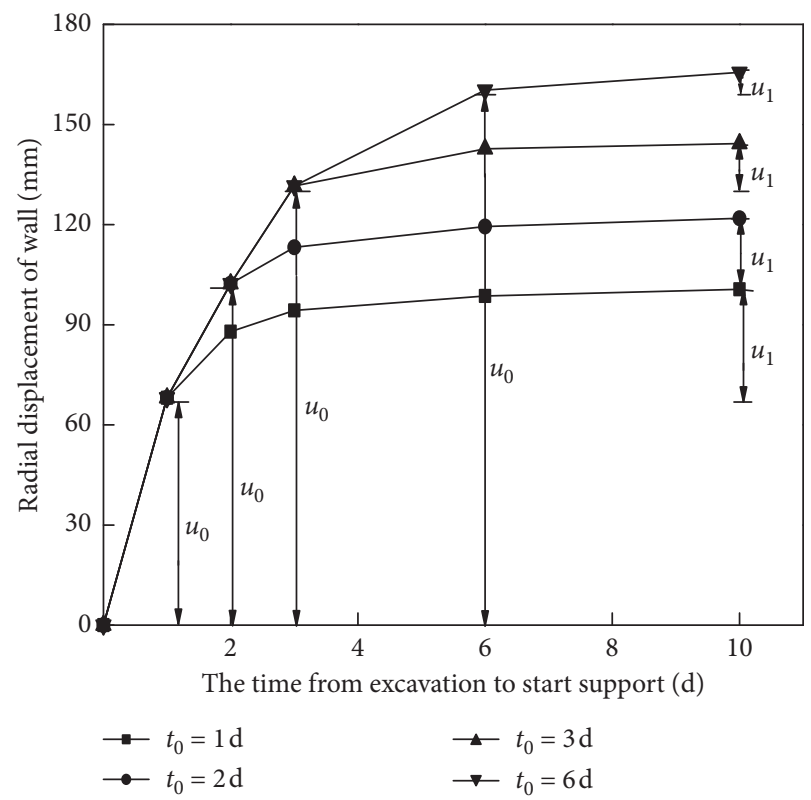

FIgURE 6: The influence of supporting opportunity on surrounding rock displacement of roadway. 
greater than $15 \mathrm{~m}$, the influence of the "space effect" on the displacement of surrounding rock can be neglected.

In the process of soft rock roadway excavation, a layer of concrete is sprayed on the excavated part to restrain the deformation of surrounding rock, and then the bolt is applied. The influence of supporting time on surrounding rock displacement is shown in Figure 6. Before the supporting is applied, a section of displacement has been produced on the wall of the roadway, which can be recorded as $u_{0}$. The displacement after the supporting is applied, which can be recorded as $u_{1}$. When the driving speed is constant, $x$ is correlated with $t_{0}$ positively. The bigger the $t_{0}$, the bigger the $u_{0}$, and the smaller the $u_{1}$. But the increase of $u_{0}$ is far greater than the reduction of $u_{1}$ and the total deformation of the tunnel wall is increasing. This is a result of the larger displacement of the roadway wall before supporting, and the limited displacement of the surrounding rock is restrained by supporting. For example, when $t_{0}$ is $6 \mathrm{~d}, u_{1}$ is only $47.4 \%$ of $u_{0}$. On the contrary, when $t_{0}$ is $1 \mathrm{~d}, u_{1}$ is only $28.8 \%$ of $u_{0}$. The total displacement is only $60.7 \%$ when $t_{0}$ is $6 \mathrm{~d}$, and the supporting effect is obvious.

\section{Conclusions}

In this paper, based on D-P strength criterion and the noncorrelation flow rule, an equivalent circular roadway solution method is proposed. The stress and deformation of surrounding rock of underground roadways are obtained by the elastoplastic theory. Then, the failure mechanism of roadway with soft rock is analyzed. Based on the D-P strength criterion, considering the softening and dilatation of surrounding rock, the surrounding rock of the roadway is divided into three zones, and the "space effect" is introduced. The analytical expressions of stress, displacement, and partition range of surrounding rock without rockbolt and lining supporting are obtained. In the process of supporting, the rockbolt is evenly arranged in the roadway, and the composite bearing body is composed of the rockbolt and the surrounding rock. The equivalent material parameters are calculated reasonably, and the elastoplastic solution of surrounding rock under the supporting condition is obtained. Therefore, considering the aging characteristics of the concrete shotcrete layer, the theoretical calculation is closer to the field engineering practice. Under the support condition, the plastic softening zone can be effectively reduced, and the plastic residual zone can be mainly reduced. Considering the "space effect" and the supporting time, the zones can be calculated more accurately. By analyzing the influencing factors of the stress and displacement of the surrounding rock, it is concluded that the spacing-row between rockbolts has little effect on the surrounding rock stress, while the influence on the displacement of surrounding rock is mainly reflected in the plastic residual zone.

\section{Data Availability}

The data used to support the findings of this study are available from the corresponding author upon request.

\section{Conflicts of Interest}

The authors declare no conflicts of interest.

\section{Acknowledgments}

This research has been supported by the National Natural Science Foundation of China (grant no. 51927807), a Project Funded by the Priority Academic Program Development of Jiangsu Higher Education Institutions (PAPD), National Natural Science Foundation of China (General Program: 52074239), and Independent Research Project of State Key Laboratory of Coal Resources and Safe Mining, CUMT (SKLCRSM18X08).

\section{References}

[1] S. S. Peng, "Topical areas of research needs in ground control a state of the art review on coal mine ground control," International Journal of Mining Science and Technology, vol. 25, no. 1, pp. 1-6, 2015.

[2] R. Wang, S. Yan, J. B. Bai et al., "Theoretical analysis of damaged width \& instability mechanism of rib pillar in openpit highwall mining," Advance in Civil Engineering, vol. 2019, Article ID 6328702, 15 pages, 2019.

[3] G. Silva, P. G. Ranjith, M. S. A. Perera, and B. Chen, "Effect of bedding planes, their orientation and clay depositions on effective re-injection of produced brine into clay rich deep sandstone formations: implications for deep earth energy extraction," Applied Energy, vol. 161, pp. 24-40, 2016.

[4] Z. Zhang, M. Deng, X. Wang, W. Yu, F. Zhang, and V. D. Dao, "Field and numerical investigations on the lower coal seam entry failure analysis under the remnant pillar," Engineering Failure Analysis, vol. 115, Article ID 104638, 2020.

[5] J. A. Bay and K. H. Stokoe, "Field determination of stiffness and integrity of PCC members using the SASW method," in Proceedings of the Nondestructive Evaluation of Civil Structures and Materials Conference, Colorado, CO, USA, October 2000.

[6] E. T. Brown, J. W. Bray, B. Ladanyi, and E. Hoek, "Ground response curves for rock tunnels," Journal of Geotechnical Engineering, vol. 109, no. 1, pp. 15-39, 1983.

[7] W. Zhu, H. Jing, L. Yang, B. Pan, and H. Su, "Strength and deformation behaviors of bedded rock mass under bolt reinforcement," International Journal of Mining Science and Technology, vol. 28, no. 4, pp. 593-599, 2018.

[8] K.-H. Park and Y.-J. Kim, "Analytical solution for a circular opening in an elastic-brittle-plastic rock," International Journal of Rock Mechanics and Mining Sciences, vol. 43, no. 4, pp. 616-622, 2006.

[9] C. Carranza-Torres, "Elasto-plastic solution of tunnel problems using the generalized form of the hoek-brown failure criterion," International Journal of Rock Mechanics and Mining Sciences, vol. 41, no. 3, pp. 480-481, 2004.

[10] Y.-K. Lee and S. Pietruszczak, "A new numerical procedure for elasto-plastic analysis of a circular opening excavated in a strain-softening rock mass," Tunnelling and Underground Space Technology, vol. 23, no. 5, pp. 588-599, 2008.

[11] T. C. Carranza and C. Fairhurst, "The elasto-plastic response of underground excavations in rock masses that satisfy the Hoek-Brown failure criterion," International Journal of Rock Mechanics and Mining Sciences, vol. 36, no. 6, pp. 777-809, 1999. 
[12] T. C. Carranza and C. Fairhurst, "Application of the convergence-confinement method of tunnel design to rock masses that satisfy the Hoek-Brown failure criterion," Tunnelling and Underground Space Technology, vol. 15, no. 2, pp. 187-213, 2000.

[13] A. Fahimifar and M. Ranjbarnia, "Analytical approach for the design of active grouted rockbolts in tunnel stability based on convergence-confinement method," Tunnelling and Underground Space Technology, vol. 24, no. 4, pp. 363-375, 2009.

[14] Z. Guan, Y. Jiang, Y. Tanabasi, and H. Huang, "Reinforcement mechanics of passive bolts in conventional tunnelling," International Journal of Rock Mechanics and Mining Sciences, vol. 44, no. 4, pp. 625-636, 2007.

[15] F. Nagel and G. Meschke, "An elasto-plastic three phase model for partially saturated soil for the finite element simulation of compressed air support in tunnelling," International Journal for Numerical and Analytical Methods in Geomechanics, vol. 34, no. 6, pp. 605-625, 2010.

[16] C. H. Tan, "Passive bolts reinforcement around a circular opening in strain-softening elastoplastic rock mass," International Journal of Rock Mechanics and Mining Sciences, vol. 88, pp. 221-234, 2016.

[17] P. P. Oreste and D. Pella, "Modelling progressive hardening of shotcrete in convergence-confinement approach to tunnel design," Tunnelling and Underground Space Technology, vol. 12, no. 3, pp. 425-431, 1997.

[18] S. Ding, H. Jing, K. Chen, G. a. Xu, and B. Meng, "Stress evolution and support mechanism of a bolt anchored in a rock mass with a weak interlayer," International Journal of Mining Science and Technology, vol. 27, no. 3, pp. 573-580, 2017.

[19] Y.-W. Pan and J.-J. Dong, "Time-dependent tunnel convergence-I. formulation of the model," International Journal of Rock Mechanics and Mining Sciences \& Geomechanics Abstracts, vol. 28, no. 6, pp. 469-475, 1991.

[20] G. Wang, Y. Zhang, Y. Jiang et al., "Shear behaviour and acoustic emission characteristics of bolted rock joints with different roughnesses," Rock Mechanics and Rock Engineering, vol. 51, no. 6, pp. 1885-1906, 2018.

[21] L. Chen, X. B. Miao, M. Li et al., "Elastoplastic analysis of cracked surrounding rock in deep roadway based on druckerprager criterion," Journal of China Coal Society, vol. 42, no. 2, pp. 484-491, 2017.

[22] M. H. Yu, G. W. Ma, and J. C. Li, Structural Plasticity, Zhejiang University Press, Hangzhou, China, 2009, in Chinese.

[23] R. Chait, "Factors influencing the strength differential of highstrength steels," Metallurgical and Materials Transactions B, vol. 3, pp. 365-371, 1972.

[24] D. C. Drucker, "Plasticity theory strength-differential(SD) phenomenon, and volume expansion in metals and plastics," Metallurgical Transactions, vol. 4, no. 3, pp. 667-673, 1973.

[25] G. C. Rauch and W. C. Leslie, "The extent and nature of the strength-differential effect in steel," Metal Trans, vol. 3, pp. 365-371, 1972.

[26] M. H. Yu, Twin Shear Theory and its Application, Science Press, Beijing, China, 1991, in Chinese.

[27] M. H. Yu and L. N. He, "A new model and theory on yield and failure of materials under the complex stress state," in $\mathrm{Me}$ chanical Behavior of Materials, International Series of the Strength and Fracture of Materials and Structures, M. Jono and T. Inoue, Eds., pp. 841-846, Pergamon Press, Oxford, UK, 1991.

[28] G. M. Zhao, R. Peng, X. R. Meng et al., "Stability of bearing structure during soft roadway excavation-supporting,"
Journal of China University of Mining \& Technology, vol. 46, no. 4, pp. 792-802, 2017.

[29] C. Yuan, W. J. Wang, and Y. L. Zhao, "Theoretical analysis on roadway surrounding rock deformation based on the properties of rock plastic hardening and softening," Journal of the China Coal Society, vol. 40, no. S2, pp. 311-319, 2015.

[30] J. W. Zhang, "Theoretical analysis on failure zone of surrounding rock in deep large-scale soft rock roadway," Journal of China University of Mining and Technology, vol. 46, no. 2, pp. 292-299, 2017.

[31] Y. Zhang, X. Zhuang, and R. Lackner, "Stability analysis of shotcrete supported crown of NATM tunnels with discontinuity layout optimization," International Journal for $\mathrm{Nu}$ merical and Analytical Methods in Geomechanics, vol. 42, no. 11, pp. 1199-1216, 2018. 